\title{
NEURINOMA CENTRAL DO NERVO ACÚSTICO
}

\author{
Paulo Pinto Pupo*
}

A localização central dos neurinomas foi descrita por Antoni, Josephy, assim como por Bielschowski, Rose, Foerster. Seu diagnóstico foi pôsto em dúvida por Cushing e Bailey, que levantaram a questão da diferenciação com o espongioblastoma polar, mas sua existência foi comprovada por MacPhhearson e Josephy, Heinze, Foersted e Gagel e por Scheinker ${ }^{1}$. A relativa raridade desta localização justifica a apresentação do seguinte caso:

H. G., brasileiro, com 45 anos de idade, casado, comerciante, sem antecedentes pessoais ou familiares de importância, que sempre foi ativo e trabalhador, procurou o Prof. Paulino W. Longo em 17-8-1944, queixando-se de tonturas e surdez progressiva à esquerda. Disse que, em fins de 1941, havia tido forte gripe com febre e que o médico assistente diagnosticou "nefrite", obrigando-o a repouso e regime durante um mês. Desde essa época não se sentiu mais bem. Sua pressão, verificada por vários médicos, oscilou sempre entre 18 e 24, para a máxima. Há 6 meses mais ou menos vem apresentando tonturas, cada vez mais intensas, distúrbios na visão com períodos de diplopia, cefaléia, e surdez progressiva à esquerda, tendo-se instalado paralisia facial à esquerda. Ao exame neurológico foi verificado: síndrome de comprometimento piramidal direito, com hemiparesia proporcional; hemianestesia à direita, respeitando a face, com comprometimento das sensibilidades táctil, térmica e dolorosa; ataxia de tipo sensitivo nos membros superior e inferior, à direita; paralisia facial periférica esquerda; hipoacusia acentuada à esquerda; sensação vertiginosa; paresia do motor ocular externo à esquercla; nistagmo horizontal ao olhar para a direita. Em sintese, sindrome de Millard-Gübler.

Em poucos dias o estado geral do paciente piorou, a pressão arterial manteve-se elevada, e o paciente faleceu sùbitamente. Foi feita a retirada dos centros nervosos exclusivamente, com permissão da família.

Necrópsia - Foco malácico na hemicalota protuberancial esquerda. Não havia tumor dos nervos periféricos, especialmente do acústico, em seu trajeto do rochedo ao tronco cerebral (fig. 1). O exame microscópico de corte transversal da protuberância (corado pelo Loyez) ao nível da emergência das raízes do nervo acústico, nível de maior extensão cio foco malácico, mostrou foco lesional comprometendo tôda a hemicalota esquerda, dela só restando intactas as fibras do feixe longitudinal posterior e, mais lateralmente, as do pedúnculo cerebelar superior, sendo que, lateralmente, estavam ainda intactas as fibras das raizes coclear e vestibular. A henicalota direita mostrava-se perfeitamente íntegra, assim como todo o pé da protube-

Trabalho do Serviço de Neurologia da Escola Paulista de Medicina (Prof. Paulino W. Longo) e do Laboratório de Anatomia Patológica do Hospital de Juqueri (Dr. Walter E. Maffei).

* Docente-Livre de Clínica Neurológica da Fac. Med. da Univ. de São Paulo e Chefe de Clínica Neurológica na Escola Paulista de Medicina. 
rância. Ao exame mais detalhado, com preparados corados pelo Loyez, hematoxilinaeosina, Van Gieson e Jacob-Mallory, assim como na impregnação pelo Perdrau e pelo Bielchowski e Hortega, notava-se a presença de um tumor em íntima conexx̃o com as fibras do acústico e um foco de amolecimento relativamente recente, que o contornava quase por completo, tendo sua maior extensão nos limites mediais e dorsais do tumor, onde tomava grande extensão da hemicalota protuberancial correspondente.

O tumor, histològicamente, apresenta-se formado por células alongadas e fusiformes, e fibrilas com disposição em palissada ou tendência à formação de turbilhões, semelhantes aos encontráveis nos neurinomas em geral (fig. 2). As células contêm pouco protoplasma; o núcleo, também fusiforme, apresenta cromatina em grânulos relativamente grosseiros; as fibrilas impregnam-se em preto pelo Perdrau, aparecendo em amarelo ao Van Gieson. Com tais característicos, concluímos tratar-se de um tumor do tipo neurinoma, isto é, tumor de nervo periférico, pela ausência de estruturas gliais ou conjuntivas. Trata-se, pois, de um neurinoma do nervo acústico e de situação intraprotuberancial. O foco de amolecimento apresenta necrose completa do parênquima nervoso em seu centro (fig. 3), vendo-se, de permeio com produtos vários de degeneração, pigmentos hemossideróticos livres ou englobados em numerosas células fagocitárias. As células nervosas adjacentes apresentam, em geral, figuras de lesão isquêmica, enquanto que há intensa proliferação glial, não só da micróglia (corpos grânulo-gordurosos), como também e principalmente, da neuróglia astrocitária, indicando já a idade do processo e a presença de fenômenos de cicatrização.

No estudo histológico da protuberância chama a atenção o aspecto de hiperplasia das paredes das arteríolas, com nítida hialinização. Como consequiência dísso, é geral a diminuição da luz vascular; em alguns dêsses vasos há verdadeira trombose. Tal aspecto é bem evidente nos preparados com o Jacob-Mallory. No bulbo há, igualmente, hiperplasia e hialinização generalizadas das paredes das arteríolas, como também nos núcleos cinzentos diencefálicos, sendo assinalado, em pleno tálamo, um foco de amolecimento microscópico, relativamente recente, ainda evidenciando produtos de desintegração em seu centro.

$\mathrm{O}$ estudo topográfico das lesões assinaladas no tronco cerebral mostra o seguinte: a) Protuberância - Neurinoma do acústico em sua porção intraprotuberancial, predominantemente em relação com as raízes vestibulares, e foco de ainolecimento em plena hemicalota esquerda, comprometendo o feixe central da calota, os lemniscos medial e lateral e as fibras do acústico, que se entrecruzam na linha mediana com as do lado oposto. Em cortes mais superiores o foco de amolecinento atinge a região dos núcleos da raiz coclear, o núcleo de Deiters e os núcleos do facial e do motor ocular externo, à esquerda. Não há comprometimento das formações da hemicalota direita, assim como do feixe piramidal e peđ̧únculos cerebelares. b) Bulbo - Em cortes transversais, corados pelo Weigert, nota-se assimetria entre as olivas (fig. 4): enquanto que a direita se apresenta com suas características normais, a esquerda mostra aumento de volume, ausência do pregueamento que lhe é peculiar, espessamento de suas lâminas e descoramento total. Ao exame microscópico ressalta a desmielinização de suas fibras aferentes e eferentes. As células nervosas são raras, em geral atróficas, algumas delas com aspecto baloniforme exagerado e acúmulo acentuado do pigmento lipocrômico, outras com figuras de degeneração isquêmica. Chama a atenção a proliferação acentuada da glia, que se apresenta principalmente sob forma de feixes espongioblásticos, entre os quais se encontram astrócitos gigantes. Tal aspecto se enquadra nas descrições clássicas de degeneração olivar secundária à lesão do feixe central da calota, exaustivamente estudada por Lhermite e Trelles2, que a descreveram como "hipertrofia olivar". Ao lado disso, há degeneração do feixe central da calota e das fibras arciformes emanadas da oliva esquerda que, entrecruzando-se na linha mediana, procuram o corpo restiforme direito; há integridade das fibras arciformes provenientes da oliva dircita. Integridade dos feixes piramidais. c) Pedúnculos cerebrais a mesencéfalo - Assi- 
nala-se a degeneração acentuada do feixe espinotalâmico e do feixe central la calota ao nível do pedúnculo, o que confere ao corte transverso um aspecto nitidimente assimétrico (fig. 5). Não nos foi possível seguir, nos cortes corados para a mielina, as fibras do feixe central da calota no mesencéfalo, quando se dissociam em direção aos seus núcleos de origem. Não hí outras alterações a assinalar no restante do encéfalo.

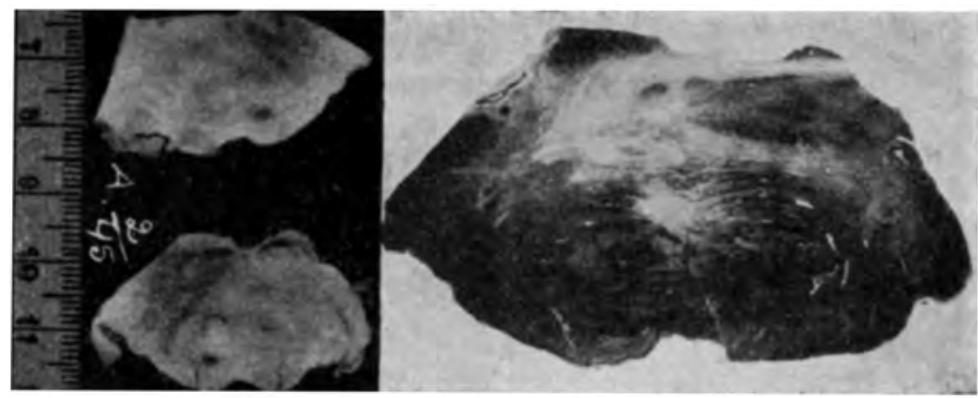

Fig. 1 - Caso H. G. Foco malácico na hemiprotuberância esquerda
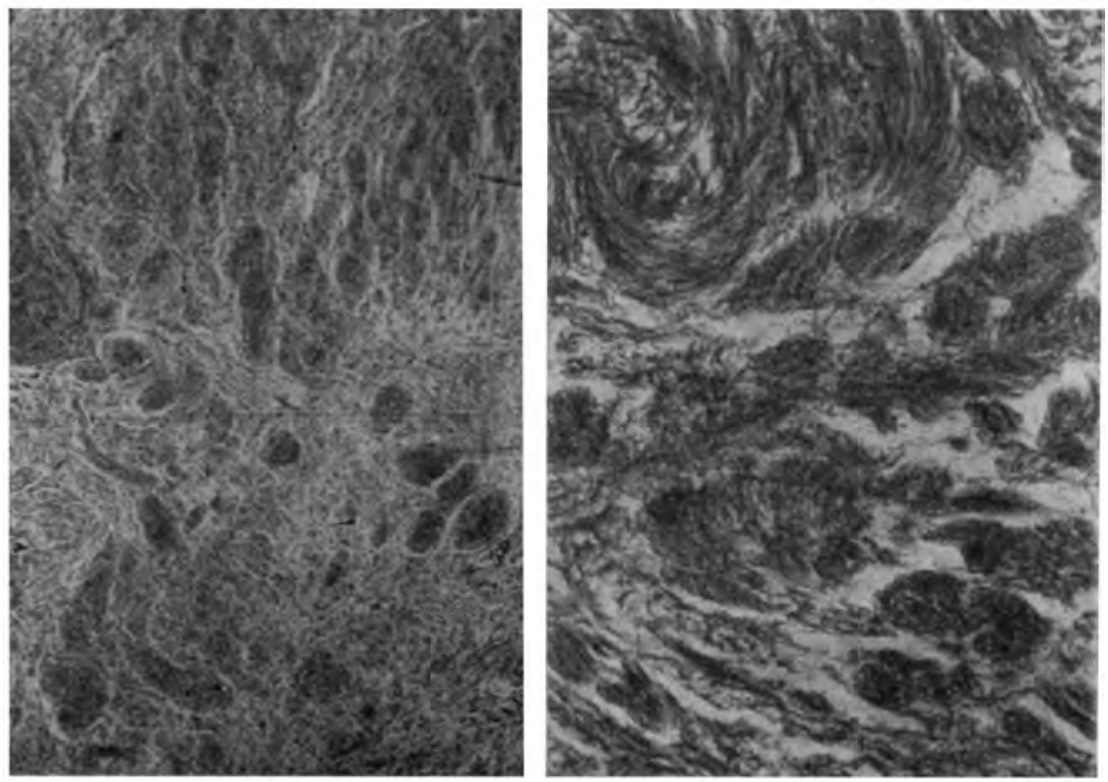

Fig. 2 - Caso H. G. Cortes histológicos do tumor intraprotuberancial (neurinoma). 


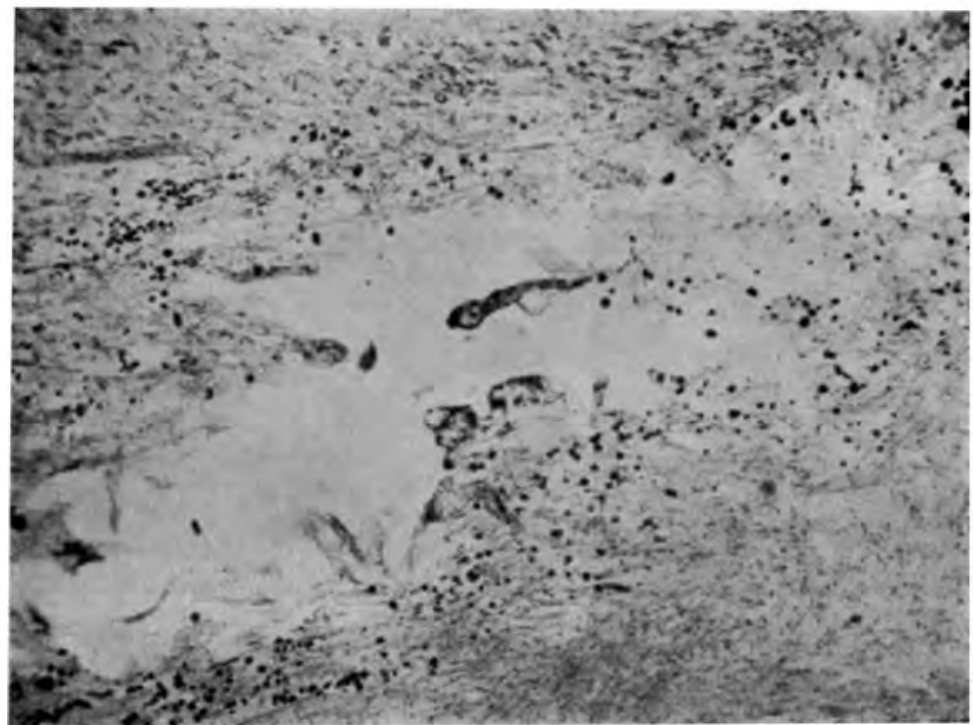

Fig. 3 -- Caso H. G. Foco de amolecimento protuberancial com necrose central.

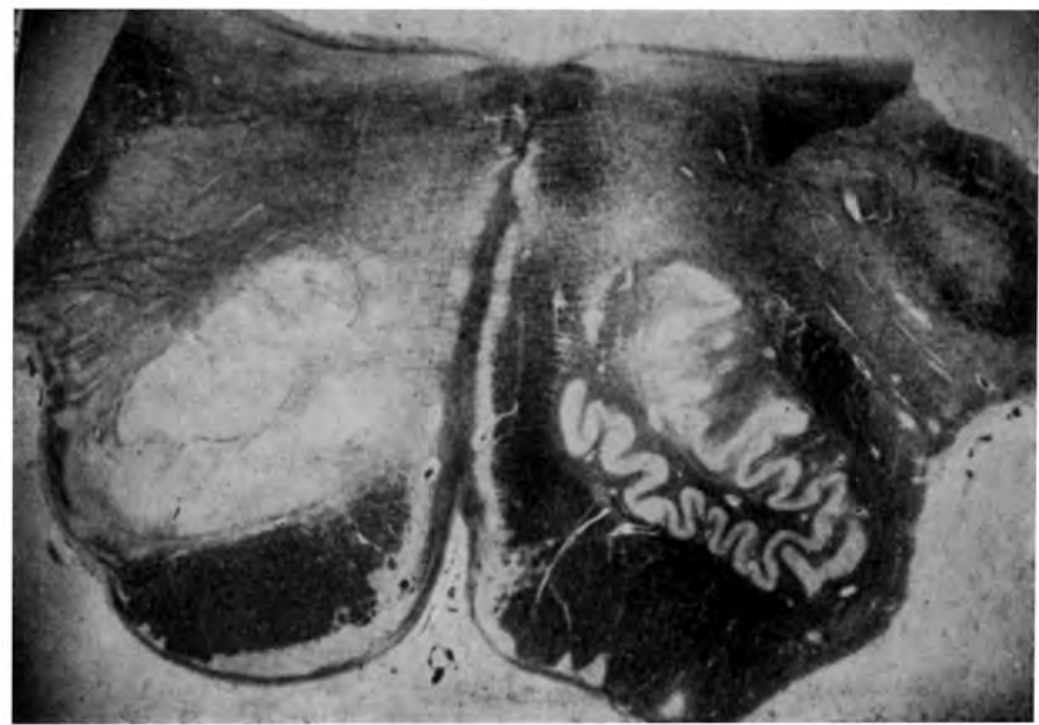

Figr. 4 - Caso H. (. Assimetria das olivas bulbares com degeneração "hipertrófica" à esquerda. 


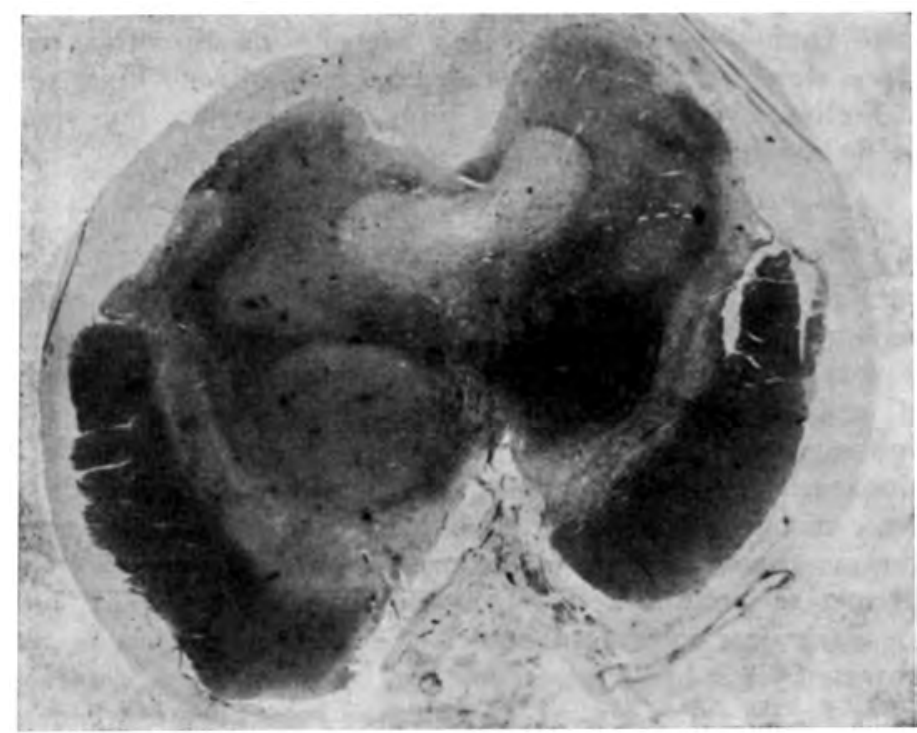

Fig. 5 - Caso H. G. Assimetria do pedúnculo cerebral

Trata-se, como vemos, de um tumor intraprotuberancial que, em seu crescimento, produziu compressões vasculares (em território vascular já bastante esclerosado) que determinaram perturbações circulatórias locais acentuadas. $O$ resultado foi a instalação progressiva de uma sindrome da calota protuberancial. A sintomatologia, conslituída por hemianestesia, hemiataxia de tipo sensitivo, comprometimento dos nervos facial, auditivo, vestibular e motor ocular externo, se explica perfeitamente pela lesão na calota protuberancial. A síndrome piramidal é mais interessante, pois que coexiste com a integridade anatômica do feixe piramidal em tôda sua extensão, o que vem mostrar, mais uma vez ${ }^{3}$, a labilidade das vias longas do sistema nervoso central às açōes nocivas mesmo de pequena intensidade (compressão por edema perifocal à lesão, por exemplo), mesmo quando o foco lesional está situado à distância. São distúrbios puramente dinâmicos, que podem oscilar de intensidade e desaparecer com a evolução do caso e a cicatrização da lesão.

O estudo histológico do tumor, mostrando o tipo de fibrilas e os núcleos em paliçada, a impregnação das neurofitrilas, assim como a ausência do elemento glial, permitiu o diagnóstico de neurinoma. Sua localização intraparenquimatosa, em plena calota protuberancial, e suas relações topográficas íntimas com as fibras intraprotuberanciais do nervo acústico, permitiram o diagnóstico de neurinoma do nervo acústico, central e solitário, colocando êste entre os raros casos similares da literatura.

Esta observação anátomo-clínica apresenta ainda a particularidade da degeneração da oliva bulbar ipsilateral à degeneração do feixe central da 
calota. lesado em nivel protuberancial. E' esta uma observação curiosa, que permite conhecimentos objetivos a respeito da discutida questão das vias olivares aferentes e do tipo da degeneração olivar "hipertrófica" descrito por Trelles. Não penetraremos aqui nesta questão, pois que ela foge ao âmbito do assunto proposto.

\section{RESUMO}

$O$ autor apresenta o caso de uma paciente com 45 anos, com hipertensão arterial, queixando-se de tonturas e surdez progressiva à esquerda que, ao exame neurológico, apresentava síndrome protuberancial, com hemi-anestesia táctil e dolorosa à direita respeitando a face, hemiparesia direita, ataxia de tipo sensitivo nos membros da direita, paralisia facial de tipo periférico, hipoacusia, paresia de motor ocular externo à esquerda, síndrome vertiginosa e nistagmo horizontal ao olhar para a direita. À necrópsia foi encontrado um tumor na hemicalota protuherancial esquerda e foco malácico adjacente, secundário a distúrbio circulatório. 0 tumor, intimamente dependente das raízes intraprotuberanciais do nervo acústico, se apresentava com as características histológicas dos neurinomas. Além dessas particularidades, a lesão do feixe central da calota e conseqüente degeneração "hipertrófica" da oliva bulbar constituem outro aspecto de grande interêsse dêste caso.

\section{SUMMARY}

The author reports the case of a women 45 years old, with arterial hypertension, with the history of dizziness and progressive deafness of left side. The neurological examination showed a pontine syndrome (right side touch and pain hypoesthesia, without disturbance on the right side of the face; right side hemiparesis with sensory type of ataxia; hypoacusia; paresis of the left abducens nerve; vertigo and horizontal nystagmus at right gaze). Necropsy showed a tumor on the left pons surrounded by a softening. The tumor was in close relation with intrapontine fibers of the 8th. nerve and showed the histological features of neurinomata. The histology showed lesion of the thalamo-olivary tract and the so-called "hypertrophic" degeneration of the inferior oliva.

\section{BIBLIOGRAFIA}

1. Scheinker, I. - Beitrag zur Frage des zentralen Neurinome. Ztschr. f. d. ges. Neurol. u. Psychiat., 55:338, 1936.

2. ( ) Lhermitte, J. e Trelles, J. O. - L'hypertrophie des olives bulbaires. Encéphale, 28:588-600, 1933. b) Trelles, J. O. - I a oliva bulbar. Estrutura, funcción y patologia. Monografia, 109 páginas, Lima, Peru, 1944.

3. Pupo, P. e Dourado, J. V. - Tumor da fossa posterior com sintomatologia atípica. Estudo anátomo-clínico de um caso de hemangioblastoma de Lindau. Arq. Neuro-Psiquiat. (S. Paulo), 3:157-169 (junho) 1945. 